Research Article

\title{
Influence of the Multicavity Shape on the Solid Scramjet
}

\author{
Pengnian Yang $(\mathbb{D}$, Zhixun Xia, Likun Ma $\mathbb{D}$, BinBin Chen, Yunchao Feng, Chaolong Li, \\ and Libei Zhao
}

College of Aerospace Science and Engineering, National University of Defense Technology, Changsha 410073, China

Correspondence should be addressed to Likun Ma; malikun@nudt.edu.cn

Received 15 July 2021; Revised 5 October 2021; Accepted 9 October 2021; Published 26 October 2021

Academic Editor: Zhen-Yu Tian

Copyright () 2021 Pengnian Yang et al. This is an open access article distributed under the Creative Commons Attribution License, which permits unrestricted use, distribution, and reproduction in any medium, provided the original work is properly cited.

\begin{abstract}
In this paper, a modular solid scramjet combustor with multicavity was proposed. The influence of multicavity shape on the performance of solid scramjet was investigated by the direct-connected tests. The experiments simulated a flight Mach 5.5 at $25 \mathrm{~km}$. The boron-based fuel-rich propellant was used. The microstructure of combustion products was analyzed by SEM. The experimental results show that the fuel-rich mixture produced by the gas generator would ignite rapidly in the solid scramjet combustor. The combustion process showed a typical characteristic of establishment-development-maintenance-attenuation. Compared to the flame-holding cavity, the other shapes of cavities, e.g., narrow and lobe, can improve mixing and combustion. In our experiment, the combustion efficiency increased from 0.41 to 0.48 , and the total pressure recovery was 0.36 . In summary, the proposed solid scramjet combustor can effectively solve the ignition delay problem of the fuel-rich mixture, and the narrow/lobe cavity shows the ability to improve the mixing and combustion of the fuel-rich mixture.
\end{abstract}

\section{Introduction}

In recent years, the strategic value of the hypersonic vehicle has gradually become prominent and therefore a hot research topic. As the most ideal power device for hypersonic vehicles, the research of scramjet has been a frontier topic [1-4]. Compared to liquid scramjet, the scramjet that uses solid fuel presents many advantages including a simple structure, high energy density, and low cost, and thus, it has attracted worldwide attention [5-8].

Research on scramjets using solid fuel has been done for more than 30 years $[9,10]$. According to the storage location of the solid fuel, scramjets have developed three configurations: solid-fuel scramjet (SFRJ), solid-fuel dual-mode ramjet combustor (SDRJ), and solid scramjet (SSRJ) [11]. Current literature suggests that the former two configurations present several technical challenges, such as low combustion efficiency, difficulties in controlling the burning rate, and the inability to work stably for long periods of time [12-14]. To solve these problems, Lv et al. proposed the SSRJ [15]. The schematic of the SSRJ is presented in Figure 1 and comprises an inlet, a gas generator, a SSRJ combustor, and a nozzle. The typical working process of SSRJ involves the selfsustained combustion of the fuel-rich solid propellant in the gas generator; this generates the fuel-rich mixture which is in turn injected into the SSRJ combustor, to combust with the airflow. Thrust is generated using a divergent nozzle [16]. Undoubtedly, the fuel-rich mixture in SSRJ enters the combustor via a transverse jet, which causes irreversible flow loss and entropy changes. However, SSRJ have high ignition reliability, good flame stability, and a flexible method for combustion organization $[17,18]$, which are unmatched by SFRJ and SDRJ. Therefore, this work is based on SSRJ.

The feasibility of SSRJ has been verified before; however, all research results published so far show that SSRJ performance has not reached the values required in many practical applications. The long ignition delay time and the low combustion efficiency of the fuel-rich mixture are among the main reasons [19-21]. Liu et al. simulated the interplay between combustor length, expansion angle, fuel-rich mixture injection angle, and the number of jet holes on SSRJ performance and provided an optimum combination [22]. 


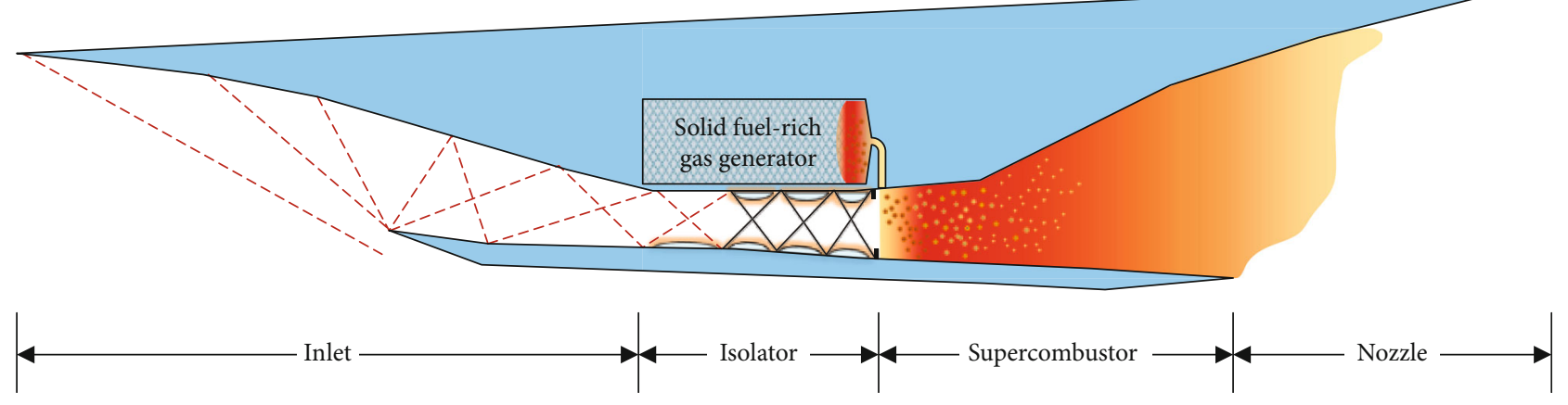

FIGURE 1: Schematic of a solid scramjet.

Yonggang et al. investigated the effect of lobe sweep angle and height on the mixing and heat release characteristics of a SSRJ combustor using numerical simulation [23]. Li et al. compared the influence of ramp, strut, and cavity combination on the SSRJ performance using both numerical simulations and experiments. The experimental results show that the ramp or strut can decrease the ignition delay time to $0.66 \mathrm{~s}$ and the combined use of cavity and strut device can improve the combustion efficiency [24, 25]. Liu et al. studied the effect of injecting the fuel-rich mixture into the cavity and demonstrated that increasing the low-speed region near the cavity and strengthening the particle recirculation can improve the performance of SSRJ [26]. Li-kun et al. carried out an experimental study on SSRJ with cavity, highlighting that the cavity can improve the combustion efficiency of a fuel-rich mixture [27]. These studies indicated that the cavity can improve the mixing and combustion of the fuelrich mixture in the SSRJ combustor. The research of liquid scramjet shows that when compared with single cavity, multicavity promotes fuel combustion more effectively [28-32]. Nevertheless, to the author's knowledge, the application of multicavity in the SSRJ is an unresearched topic.

In this study, a modular scramjet combustor with a multicavity combustor is designed, including two new cavity shapes. The influence of cavity shapes on the performance of SSRJ was compared in two experiments. These experiments simulated the flight environment of Mach 5.5 at $25 \mathrm{~km}$. The boron-based fuel-rich propellant is used in this study. In Section 2, the test platform and procedure are introduced. In Section 3, the influence of cavity shape on the SSRJ is analyzed carefully. In Section 4, some valuable conclusions are summarized.

\section{Experimental Apparatus and Procedure}

2.1. Test Platform. The experiments are conducted on a direct-connected test platform of the National University of Defense Technology, as shown in Figure 2. The test platform mainly comprises an air heater, the tested SSRJ combustor, a direct-connected experimental bench, and data acquisition equipment.

In this study, the air heater manipulates the combustion process to simulate the flight environment of Mach 5.5 at $25 \mathrm{~km}$. Ethanol $\left(\mathrm{C}_{2} \mathrm{H}_{5} \mathrm{OH}\right)$, oxygen $\left(\mathrm{O}_{2}\right)$, and compressed air are burnt in the air heater with an accurate mass flow ratio to preserve the oxygen concentration by weight of about $23.3 \%$. The key parameters of the air heater include the mass flow rate $(\sim 1 \mathrm{~kg} / \mathrm{s})$, total temperature $(\sim 1550 \mathrm{~K})$, and total pressure $(\sim 1.1 \mathrm{MPa})$. The air heater outlet uses a nozzle to accelerate the air to Mach 2.4.

2.2. The Data Acquisition and Control System. During the test, thrust (the bench), pressure (the air heater, gas generator, and wall pressure along the combustor), and mass flow rate (the air, ethanol, and oxygen) are measured with \pm $0.5 \%$ accuracy by data acquisition system. A force sensor with a range of $0-5 \mathrm{kN}$ measures thrust, while pressure sensors, with an operating range of $0-10 \mathrm{MPa}$, are used to register the high pressure in the air heater and gas generator. Additionally, an integrated pressure scanner at an operating range of $0-0.8 \mathrm{MPa}$ measures the low pressures, such as the wall pressure along the combustor. Finally, turbine flowmeters measure the air, ethanol, and oxygen mass flow rates. All data are sent to the control system via high-speed Ethernet and are displayed on a monitor in real time. Simultaneously, the experiment is recorded with a high-speed camera.

A typical experimental procedure is as follows: Initially, the air heater is ignited. When the flow reaches a stable condition, the fuel-rich solid propellant within the gas generator is ignited. Then, the fuel-rich mixture produced by the solid propellant is injected into the SSRJ combustor, where it mixes and combusts with the airflow originating from the air heater. Finally, the high-temperature and high-pressure combustion products expand and accelerate via the supersonic nozzle and generating thrust.

To ensure the normal implementation of the experiment, an accurate sequence of the startup is mandatory during the test. The sequence is executed by the control system, with the startup sequence used in this study as shown in Table 1.

2.3. Solid Scramjet Combustor. In order to improve the facilities of the experiment, a modular SSRJ combustor is proposed. The SSRJ combustor is a symmetrical rectangular structure composed of a chamber shell and an internal profile. The SSRJ combustor can be modified by replacing the internal profile. The configuration and the detailed dimensions of the SSRJ combustor are shown in Figure 3. 


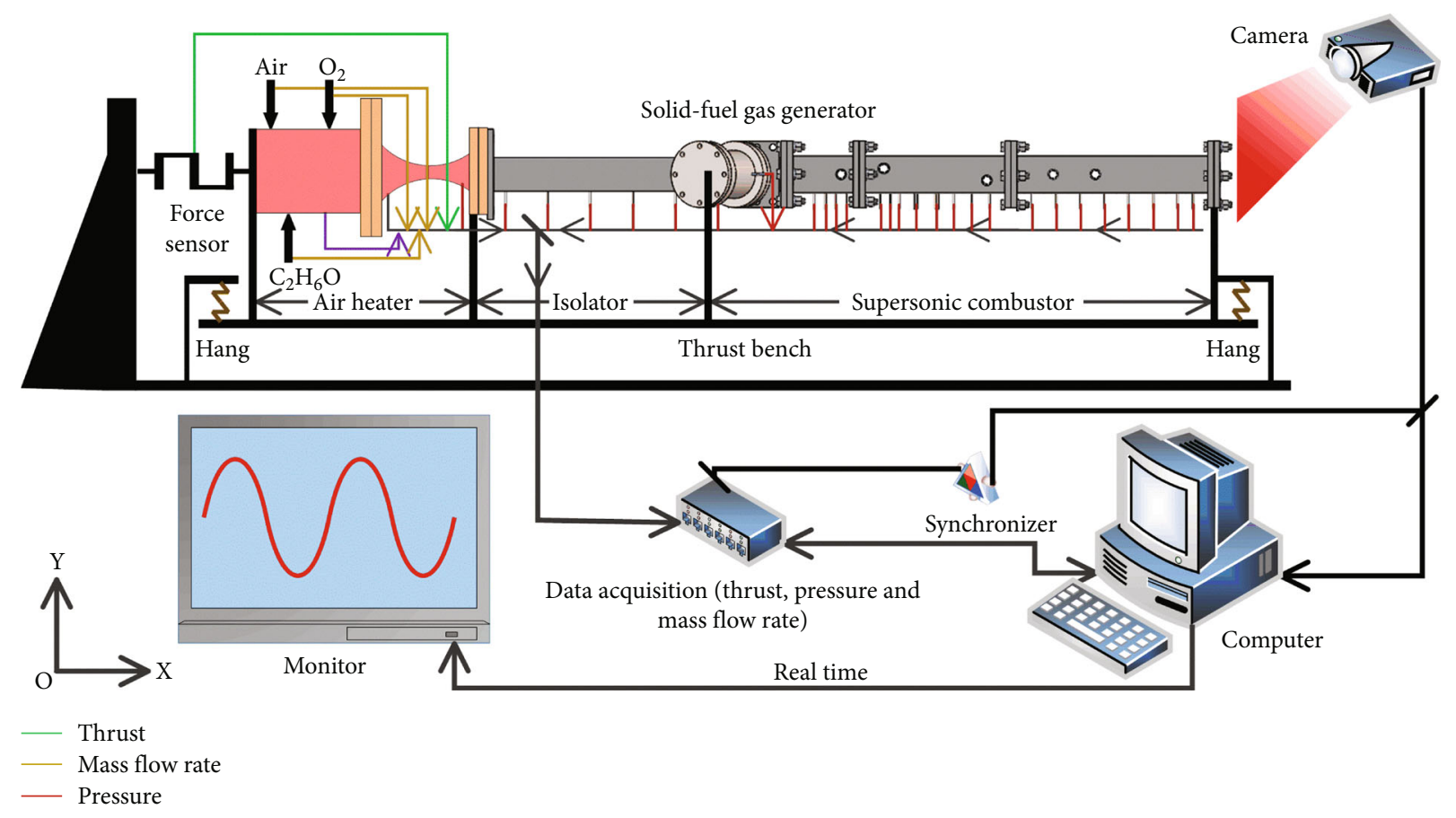

FIGURE 2: Schematic of the experimental apparatus.

TABLE 1: Startup sequence.

\begin{tabular}{lc}
\hline Time $(\mathrm{s})$ & Instruction \\
\hline 0 & Start \\
6.07 & Air value on \\
6.25 & Oxygen and ethanol valves on \\
6.55 & Air heater ignition \\
11.10 & Gas generator ignition \\
37.05 & Oxygen and ethanol valves off \\
43.05 & Air valve off \\
50 & End \\
\hline
\end{tabular}

The SSRJ combustor consists of four main parts:

(a) Gas generators: two gas generators that are symmetrically installed on the combustor. The boron-based fuel-rich propellant (boron mass fraction: $33.5 \%$ ) is self-sustaining combustion in the gas generator to produce the fuel-rich mixture, which usually comprises of combustible gas $\left(\mathrm{CO}, \mathrm{H}_{2}\right.$, etc. $)$ and condensates particles (boron and carbon). The mass flow of the fuel-rich mixture is determined by [25]:

$$
\dot{m}_{\mathrm{gas}}=a p_{\mathrm{gas}}^{n} \rho_{p} A_{p}
$$

where $a$ is the burning rate coefficient and $n$ is the pressure exponent. $\rho_{p}$ and $A_{p}$ are the density and burning area of the solid propellant, respectively. It is worth mentioning that the parameters introduced above are determined by the propellant itself. In other words, after the boronbased fuel-rich propellant is produced, the values of $a, n$, $\rho_{p}$, and $A p$ are determined accordingly. $p_{\text {gas }}$ is the pressure in the gas generator, which is affected by the combined effects of the propellant properties and the throat area. The above shows that the mass flow of the fuel-rich mixture is determined by $p_{\text {gas }}$.

(b) Solator: the constant cross-sectional isolator preventing the intake unstart due to high pressure generated within the supersonic combustor. The height and width of the isolator are $40 \mathrm{~mm}$ and $50 \mathrm{~mm}$, respectively

(c) Injector: the injector is used to inject the fuel-rich mixture produced in part (a) into the supersonic combustor. A backward step connects part (b) to part (a), which can effectively prevent the pressure of the combustor from affecting the working state of the inlet

(d) Supersonic combustor: the expanded combustor consists of a chamber shell and internal profile. The chamber shell has a rectangular shape with equal cross section, and the internal profile is designed according to the needs. The chamber shell and internal profile are connected by bolts or lap joints of steps, as shown in Figure 4

2.4. Cavity Shape. Four cavities being utilized in the test SSRJ combustor to enhance the combustion are arranged symmetrically on both sides of the combustor. The cavity position (front and back) and size are presented in Figure 5. 


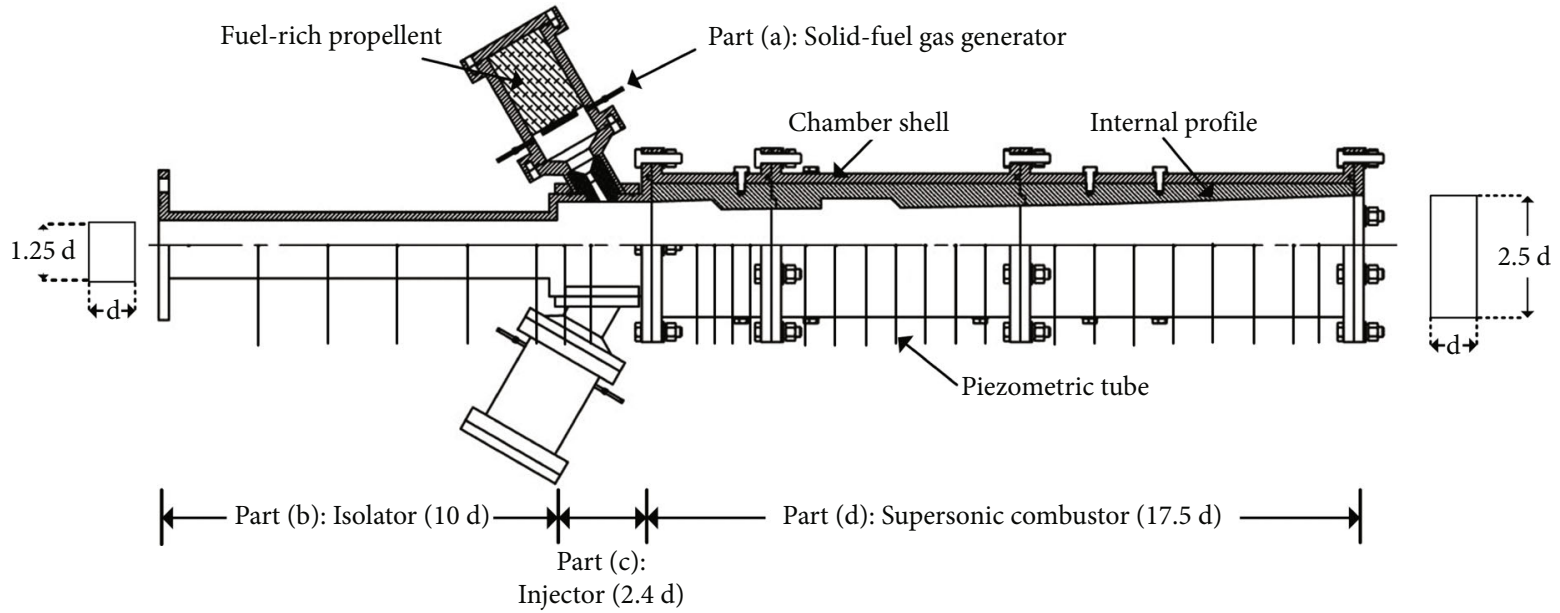

FIgURE 3: Schematic of the solid scramjet combustor.

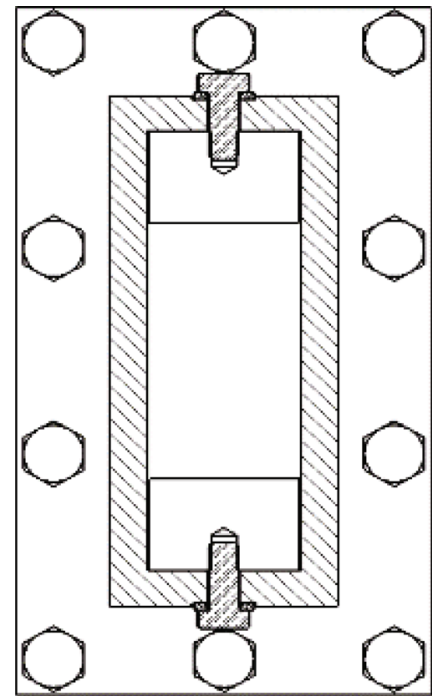

(a) Connected by bolts

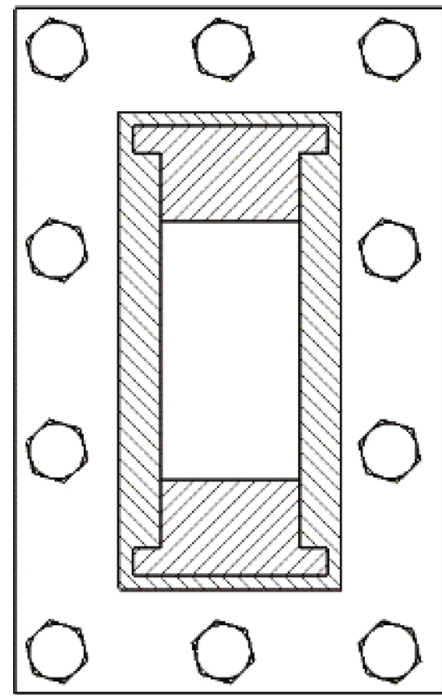

(b) Connected by lap joints of steps

FIGURE 4: The chamber shell and the internal profile connection mode.

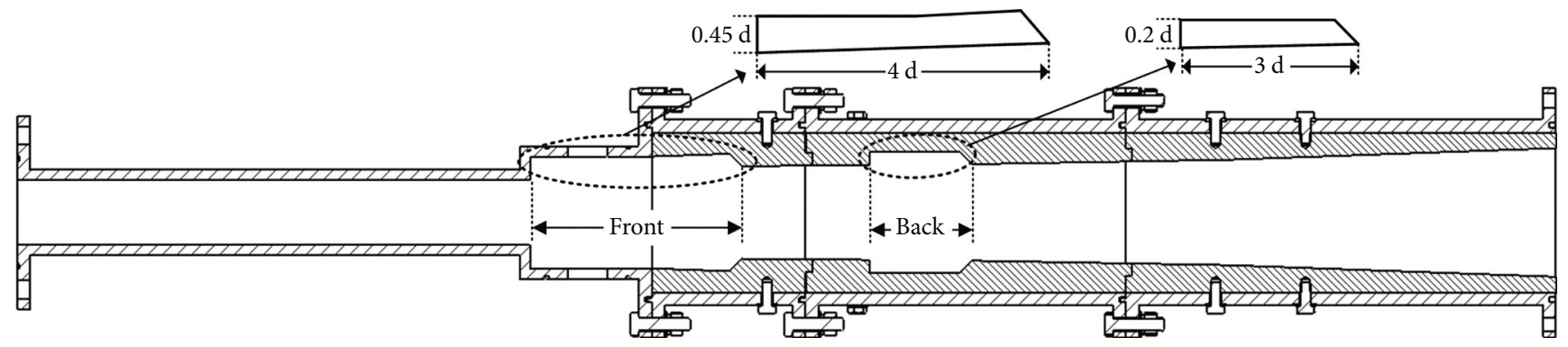

Figure 5: Schematic of the cavity position and size.

Based on a flame-holding cavity (Figure 6(a)), two kinds of unconventional cavities are proposed, i.e., narrow cavity (Figure 6(b) and lobe cavity (Figure 6(c)). The lobe cavity involves a lobe structure aiming to produce a streamwise vortex to enhance the mixing, and the narrow cavity is aimed at investigating the influence of the span size of the cavity on the combustion.
2.5. Test Cases. The purpose of this study is to explore the working performance of a SSRJ utilizing a gas generator on both sides and to investigate the combustion enhancement effect of the multicavity device. Additionally, we also study the influence of the other shape cavities, i.e., lobe cavity and narrow cavity, on the mixing combustion of the SSRJ. The shape of the cavity is presented in Table 2 . 

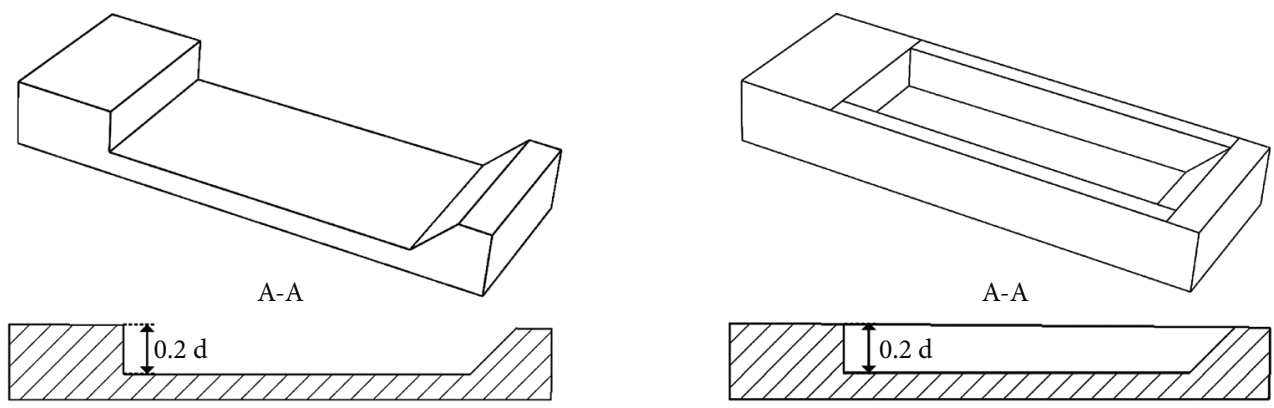

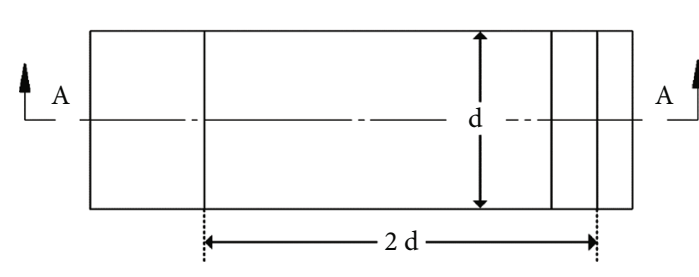

(a) Flame-holding cavity

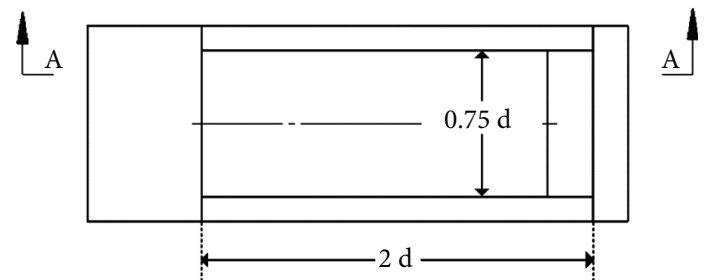

(b) Narrow cavity

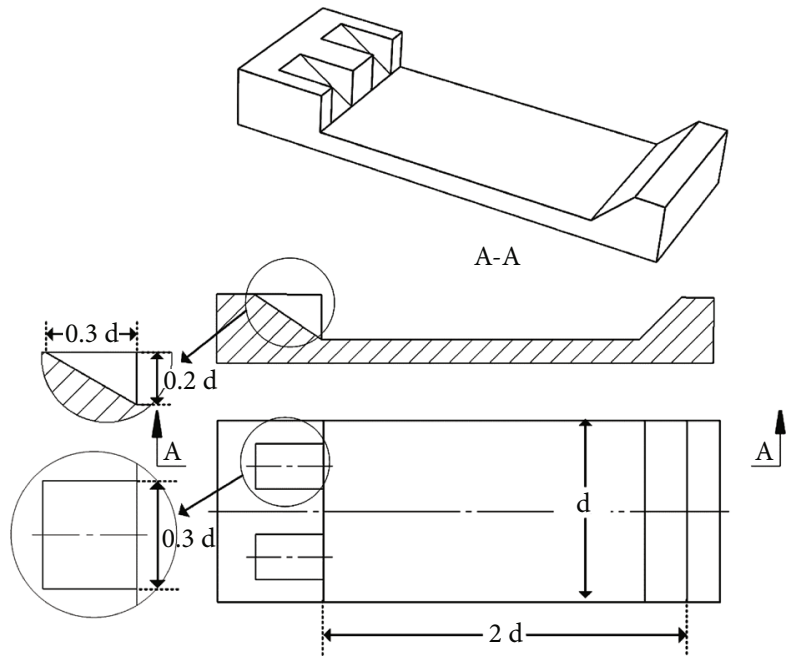

(c) Lobe cavity

FIGURE 6: Schematic of the cavity shape.

TABLE 2: The shape of the cavity shape in test case.

\begin{tabular}{lcc}
\hline \multirow{2}{*}{ Test no. } & \multicolumn{2}{c}{ Cavity shape } \\
& Front position & Back position \\
\hline 1 & Flame-holding & Flame-holding \\
2 & Narrow & Lobe \\
\hline
\end{tabular}

\section{Results and Discussion}

3.1. Operating Characteristics of the Solid Scramjet. The pressure-time $(P \sim t)$ curves of the gas generator during the tests are illustrated in Figure 7 . It can be seen that during the tests, the pressure of the gas generator is not constant and gradually increases. However, the increase rate decreases gradually, while at the end of the tests, the pressure decreases rapidly. It is usually believed that both the propellant burning area and the throat deposition may influence the pressure of gas generator. This analysis shows that the expansion/reduction of the propellant's burning area is the main reason for the rapid change of the pressure at the beginning/end of the test, while the slow pressure variation is mainly caused by the deposition and shedding of the fuel-rich mixture in the throat.

From Equation (1), it follows that when the pressure index is $n>0$, the pressure is positively correlated with the flow rate of the fuel-rich mixture. Therefore, the mass flow rate of the fuel-rich mixture gradually increases during the test. It is worth noting that once the gas generator starts operating, the burn area and the throat deposition are uncontrolled, leading to an inconsistent working process despite the same gas generator is used in both tests. Specifically, the working time of the two gas generators has a time difference of $2 \mathrm{~s}$ in test 2 . The way to control the working process of the gas generator is a topic that requires further study.

The thrust-time $(F \sim t)$ curve and the equivalence ratetime $(\varphi \sim t)$ curve of the tests are shown in Figure 8, with 


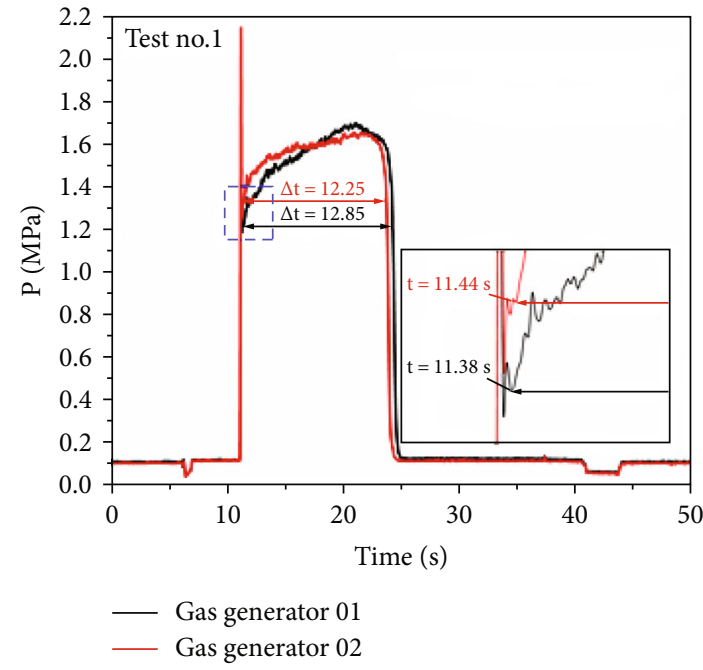

(a)

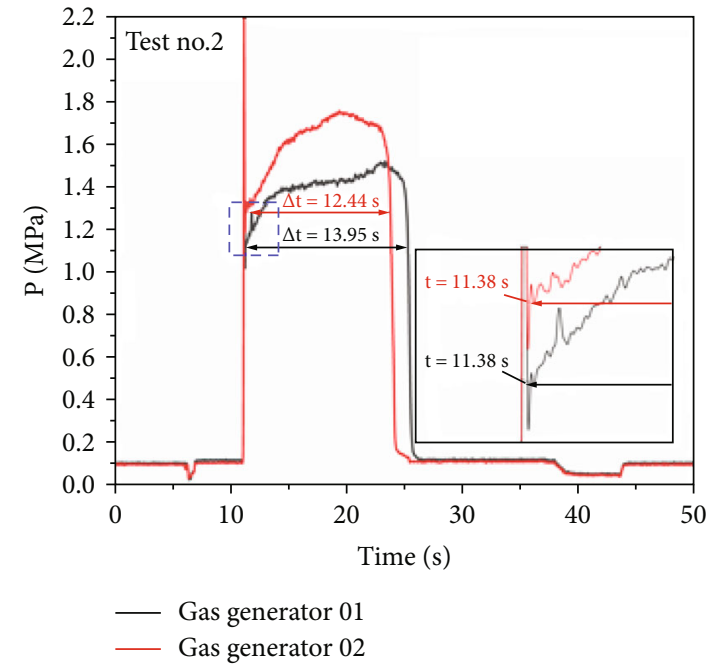

(b)

Figure 7: Pressure evolution in the gas generator.

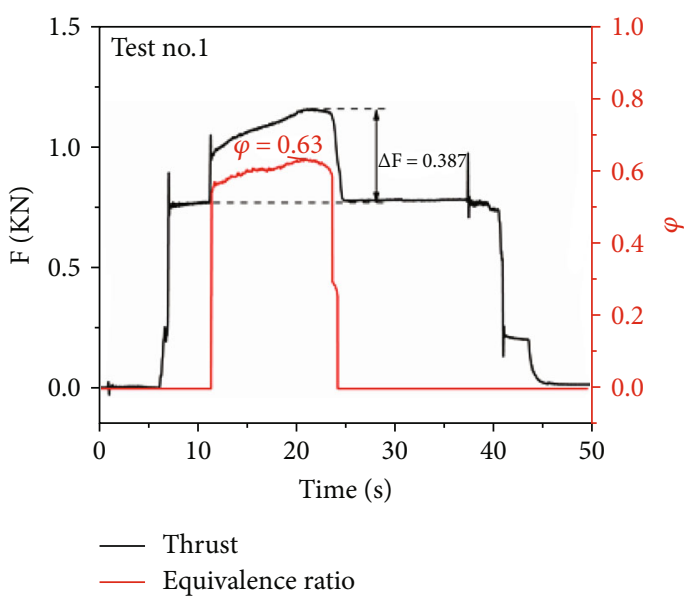

(a) Test 01

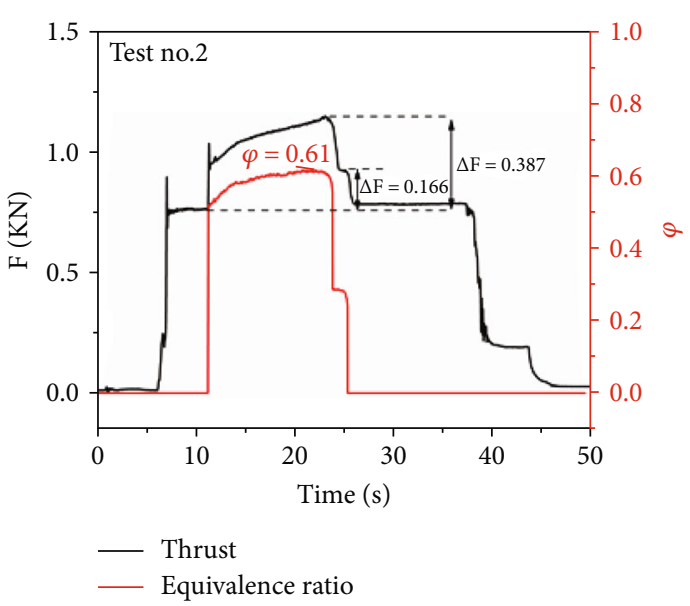

(b) Test 02

FIGURE 8: Evolution of the thrust and equivalence ratio.

the equivalence ratio determined by the following:

$$
\varphi=\frac{\left(\dot{m}_{\text {air }} / \dot{m}_{\text {fuel }}\right)_{\text {stoic }}}{\left(\dot{m}_{\text {air }} / \dot{m}_{\text {fuel }}\right)}
$$

where $\dot{m}_{\text {air }}$ and $\dot{m}_{\text {fuel }}$ are the mass flow rate of air and fuelrich mixture, respectively, and the footnote stoic is the stoichiometric state. When the propellant type and the airflow rate of the heater are determined, the equivalence ratio directly reflects the mass flow rate of the fuel-rich mixture.

From Figure 8, that for both tests, once the gas generator ignites, the thrust increases sharply (about $200 \mathrm{~N}$ ) and then continues to increase gradually and thereafter levels off. The thrust and the equivalent ratio change simultaneously, revealing the basic relationship between the two; namely, the more fuel exploited, the greater the thrust. Figure 8 also shows that the thrust of the SSRJ has the ability of a continuous and abrupt adjustment.
An interesting point is that in test 2 , due to the different operating times of the gas generator, only a single gas generator worked in the late test period, which caused the equivalence ratio to drop from 0.6 to about 0.3 . However, under this state, the thrust indicates that the fuel-rich mixture is still burning in the SSRJ combustor, which proves that the experimental SSRJ has the potential to operate in a wide range.

3.2. Ignition and Combustion. A high-speed camera was used to record pictures of the SSRJ exhaust flame during the test. Although the exhaust flame is not enough to assume the flame in the SSRJ combustor, our analysis below suggests that the characteristics of the exhaust flame partially reflect the degree of mixing and combustion of the fuel-rich mixture in the combustor and also show the different combustion characteristics of gas and particles in the fuel-rich mixture. 

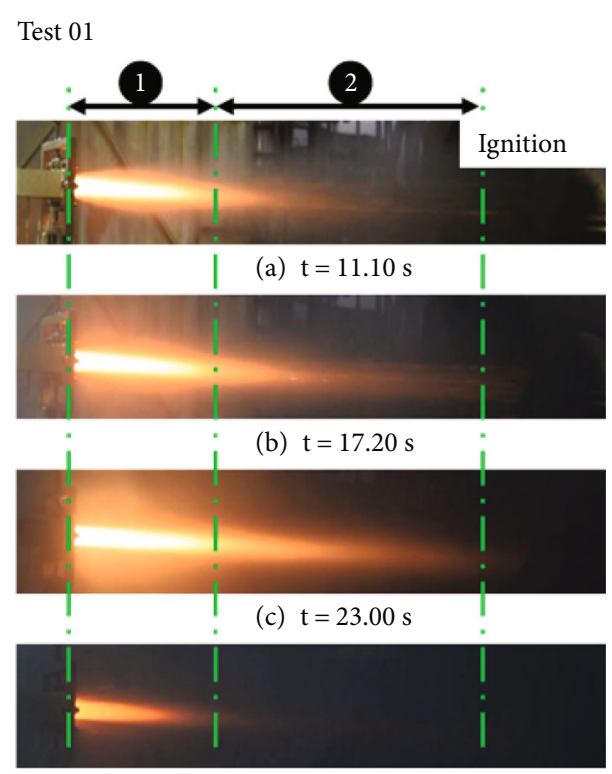

(d) $\mathrm{t}=24.00 \mathrm{~s}$
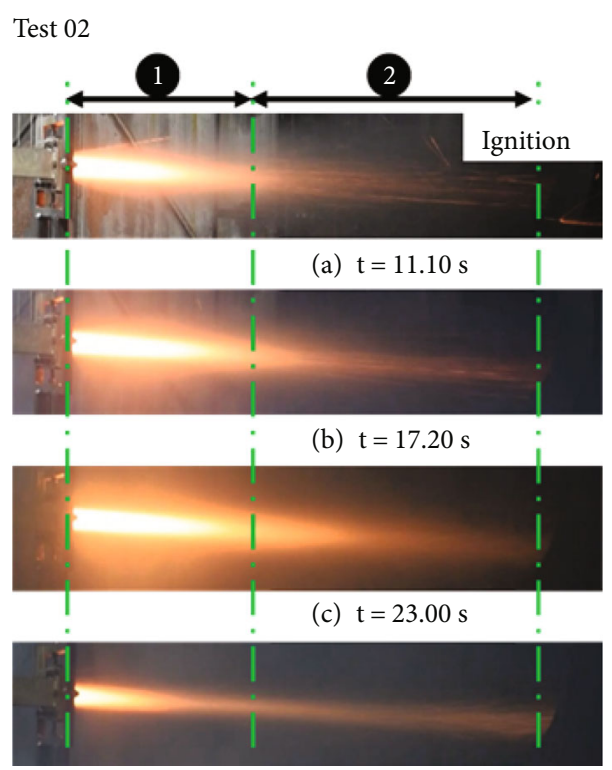

(d) $\mathrm{t}=24.00 \mathrm{~s}$

Figure 9: Solid scramjet exhaust plume.

The SSRJ exhaust plume is shown in Figure 9, and it can be divided into the bright zone (zone 1) and the dark-yellow zone (zone 2). During the tests, the shape of zone 2 significantly changed, compared to zone 1 . Meanwhile, particle trajectories associated with incomplete combustion can be clearly observed in zone 2 . The fuel-rich mixture comprises gas and particles and by comparing the combustion characteristics of the two phases. It is considered that the shape of zone 1 is dominated by gas combustion. Due to the stable combustion of gas and the concentrated heat release, zone 1 is basically unchanged, while the shape of zone 2 reflects the combustion state of the particles. The particles gradually ignite with the establishment of combustion in the SSRJ combustor, which causes obvious changes in zone 2. However, a large number of particle trajectories can be observed in the exhaust plume, indicating that the particles are not completely combustion and the combustion efficiency is low.

The color and length of the exhaust plume reflect the amount of heat released. From the images of exhaust plume of both tests, it is evident that the fuel-rich mixture entering the SSRJ combustor can achieve a rapid ignition, and there is no ignition delay as mentioned by $\mathrm{Li}$ et al. In addition, the color and length of the exhaust plume in test 2 (especially zone 1) are better than that in test 1 , indicating that the mixing and combustion of the fuel-rich mixture in test 2 are superior than that of test 1 .

In order to obtain the flow information inside the SSRJ combustor, we arranged 26 piezometric tubes on the internal wall. The position of the piezometric tubes is shown in Figure 10. The pressure in the combustor during the test was obtained using an integrated pressure scanner, with 50 frame/s collection frequency.

By linearly interpolating in time and space the collected pressure values, we obtained the combustor pressure contours during the test; see Figure 11. It can be seen that the high-pressure areas are formed at the cavity, indicating that the cavity is conducive to maintaining the high-pressure environment in the combustion, which plays an important role in stabilizing the flame. The location of the front cavity is the area with the highest pressure, indicating that the fuelrich mixture reacts quickly at this location and releases a lot of heat.

Comparing the contours of the front cavity location in the two tests, it was found that test 1 basically realized isobaric combustion. In addition, the high-pressure range of test 1 is bigger than test 2 . By comparing the same position in test 1 , it is evident that the lobe structure (the dashed orange wireframe in test 2) did not maintain the highpressure environment in the combustor, but inhibited the pressure of the forward transfer and reduced the working load of the isolator. At the same time, it can be seen that the position of the cavity's back edge caused sudden pressure changes, indicating that there is a shock wave with high intensity near the dashed orange wireframe seen in Figure 11 (test no. 1). However, the shock wave intensity gradually weakened as the test progresses. It is speculated that this is mainly due to the gradual ablation of the cavity's back edge, as shown in Figure 12.

The $P-t$ curves of the combustor wall pressure at different instants during the tests are illustrated in Figure 13. It can be seen that the high-pressure area of the combustor is practically the same as the cavity position, which is consistent with the above analysis. As the test progressed, the pressure in the combustor continued to rise, indicating that the combustion became more intense. To balance the pressure at the combustor and isolator, a shock train is generated in the isolator and moves forward, but it does not affect the pressure at the inlet of the isolator. The latter indicates that the isolating section used in the test is effective. Combined with the change in the equivalence ratio during the test, we speculate that the 


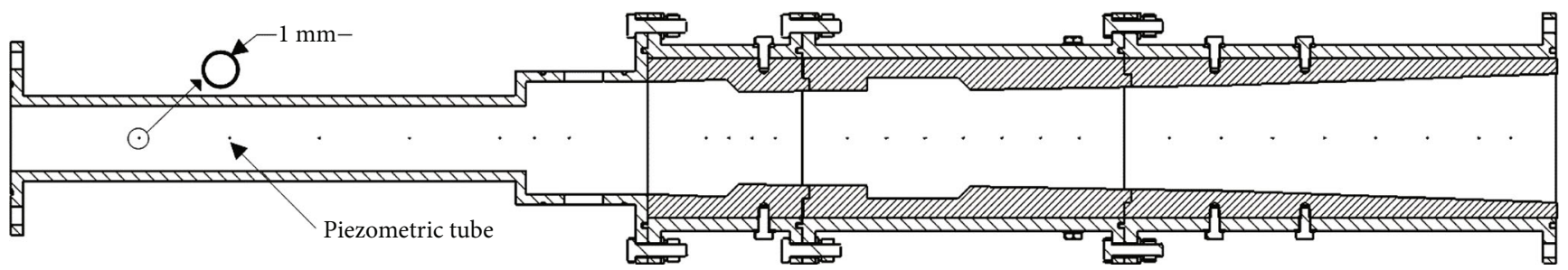

FIGURE 10: Schematic of the pressure measuring points.
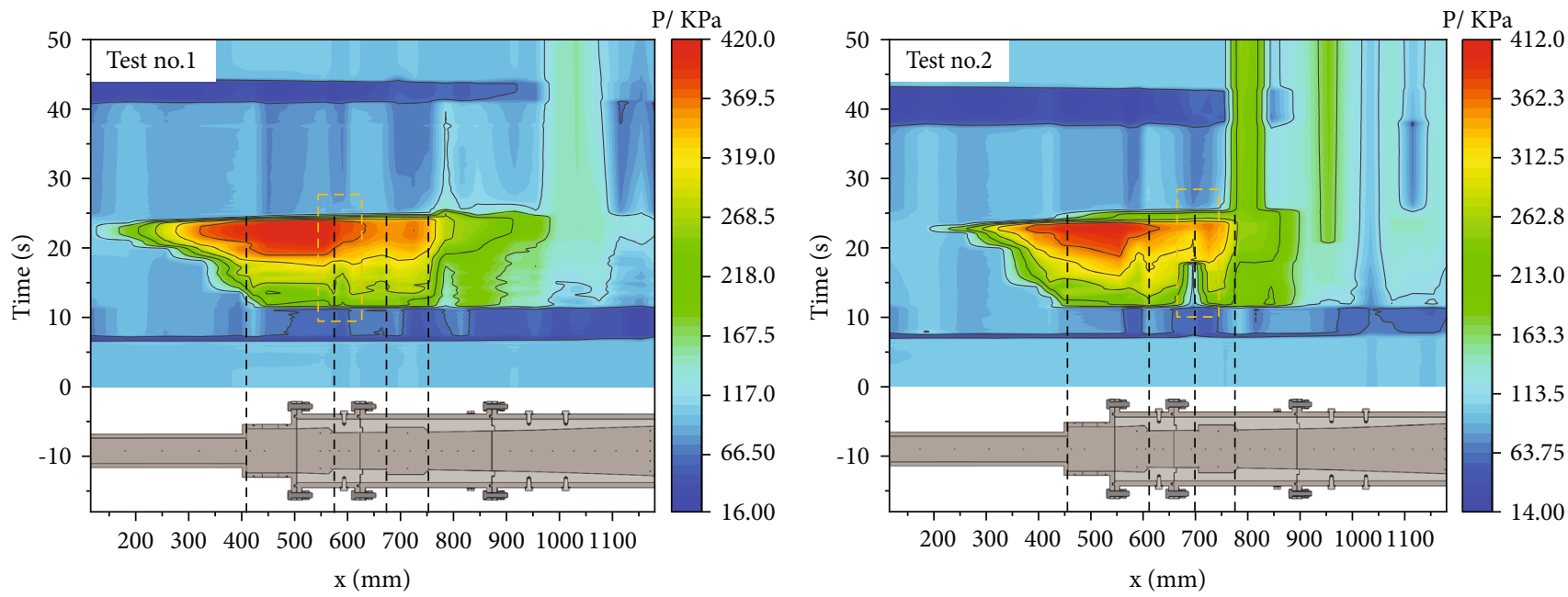

Figure 11: Combustion pressure contour map.
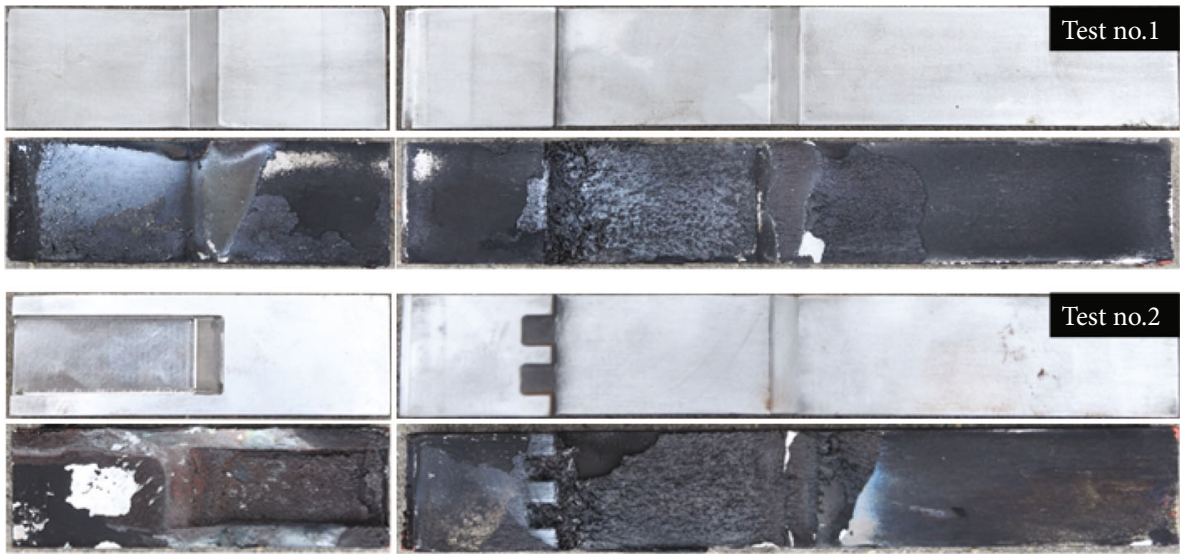

Figure 12: Schematic of the cavity structural changes before and after the test.

pressure drop in the combustor at the end of the test was caused by the reduction of the fuel-rich mixture.

Next, combine the gas generator pressure (Figure 7), the exhaust flame (Figure 9), and the pressure contours (Figure 11) to analyze the combustion process of the fuelrich mixture with the supersonic air. The detailed process is as follows:

(a) Establishment: the pressure of the gas generator rises rapidly, the combustor pressure is low, and the flame is short (b) Development: the rate of increase in the pressure of the gas generator slows down, the pressure of the combustor increases gradually, the exhaust plume tends to be stable, and the particles start burning

(c) Keep: the pressure of the gas generator increases slowly, the combustor maintains a high pressure, and the shape of the exhaust flame is stable

(d) Attenuation: the pressure of the gas generator and the combustor drops rapidly. The exhaust plume disappears gradually 

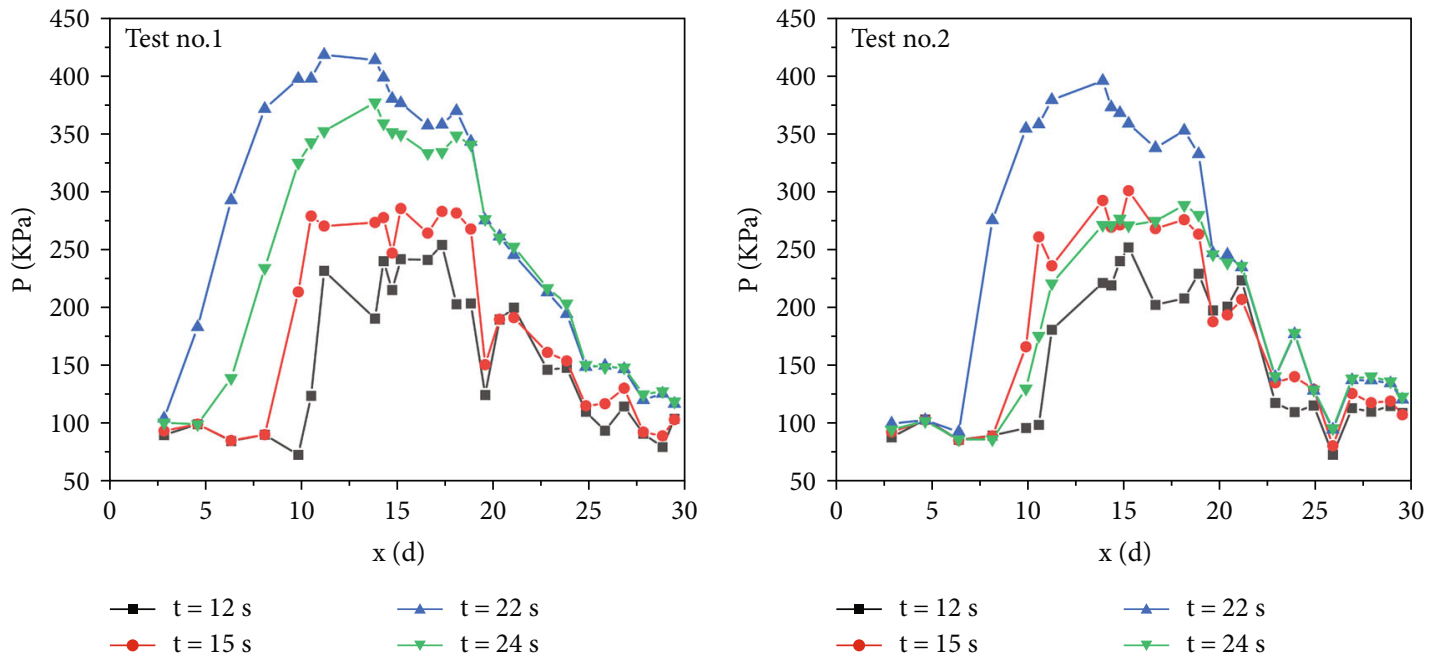

FIGURE 13: The wall pressure at different timings.

The above process is also consistent with the characteristics of flame stability in the cavity of the liquid scramjet, that is, the process of combustion from local to the entire combustor.

The structure of the cavity before and after the test is shown in Figure 12. The changes of the cavity in the two tests have the same characteristics as follows: the front edge of the cavity is intact, but the back edge is ablated, and the front cavity is more severe; the bottom wall of the front cavity is complete but the back is ablated; there are fewer particles deposited in the front cavity, but a large number of articles deposited in the back.

The above phenomenon shows that the heat release is concentrated near the front cavity. After colliding in the flow channel, the particles move towards the wall and flow into the back cavity, where a large number of particles are deposited. It is speculated that the ablation of the front cavity is mainly caused by high temperature, while the back cavity is caused by the erosion of particles and high temperature.

3.3. Product Analysis. In order to investigate the change of the particle morphology, the combustion products are collected to observe their microstructure by scanning electron microscope (SEM). Figure 14 presents the SEM picture of the products at the gas generator throat. It can be seen that the products exist in the form of agglomerates with a loose texture and uniform overall distribution. The particle size of agglomerates is less than $5 \mu \mathrm{m}$ and comprises of two particle types with an obvious size difference. The typical characteristics are shown in the blue ring and the yellow ring, respectively. According to Reference [33], the blue ring is boron particle (particle size of about $1 \mu \mathrm{m}$ ), and the yellow ring is carbon particle (particle size of about $0.1 \mu \mathrm{m}$ ). The smaller size of particle contributes to the good fluidity of particles.

To further analyze the combustion process of the particles, Figure 15 presents the SEM picture of the products at the throat of the gas generator, the bottom wall of the back cavity, and the outlet of the combustor. The micromorphology of the product has several dissimilarities at each location: the particles in the throat of the gas generator are evenly distributed, completing in shape, and polymerized. The shape of the particles in the cavity has changed, and the surface of the test product is smooth and has a large number of pores, which can be considered that the smooth surface is formed by the cooling of the molten particles, and the pores are caused by the gaseous products released from the combustion of the particles. Additionally, the morphology of the particles at the outlet of the combustor is between the two cases presented above, and some particles are sintered.

In addition, a large number of carbon particles are observed at all locations. The characteristic residence time of the working fluid is about $1 \mathrm{~ms}$. Theoretical calculation shows that $1 \mathrm{~ms}$ is enough to make the carbon particle (particle size $0.1 \mu \mathrm{m}$ ) burn thoroughly; however, the experimental results indicate that the combustion characteristics of particles in the fuel-rich mixture have changed compared with pure carbon/boron particles. The reason for this change needs to be further studied.

3.4. Performance of the Solid Scramjet Combustor. In this work, parameters such as combustion efficiency, total pressure recovery coefficient, and specific impulse of the thrust augmentation were selected to quantitatively analyze the influence of different shapes of cavities on the SSRJ combustor performance.

The combustion efficiency, $\eta_{\Delta h}$, is defined as the ratio between the experimental and theoretical total temperature changes of the mixture in the SSRJ combustor [34]:

$$
\eta_{\Delta h}=\frac{\left(T_{t, \exp }\right)_{e}-\left(T_{t, \exp }\right)_{\text {in }}}{\left(T_{t, \text { the }}\right)_{e}-\left(T_{t, \exp }\right)_{\text {in }}},
$$

where footnote $e$ represents the outlet of the combustor, and the theoretical total temperature, $\left(T_{t, \text { the }}\right)_{e}$, is obtained from 

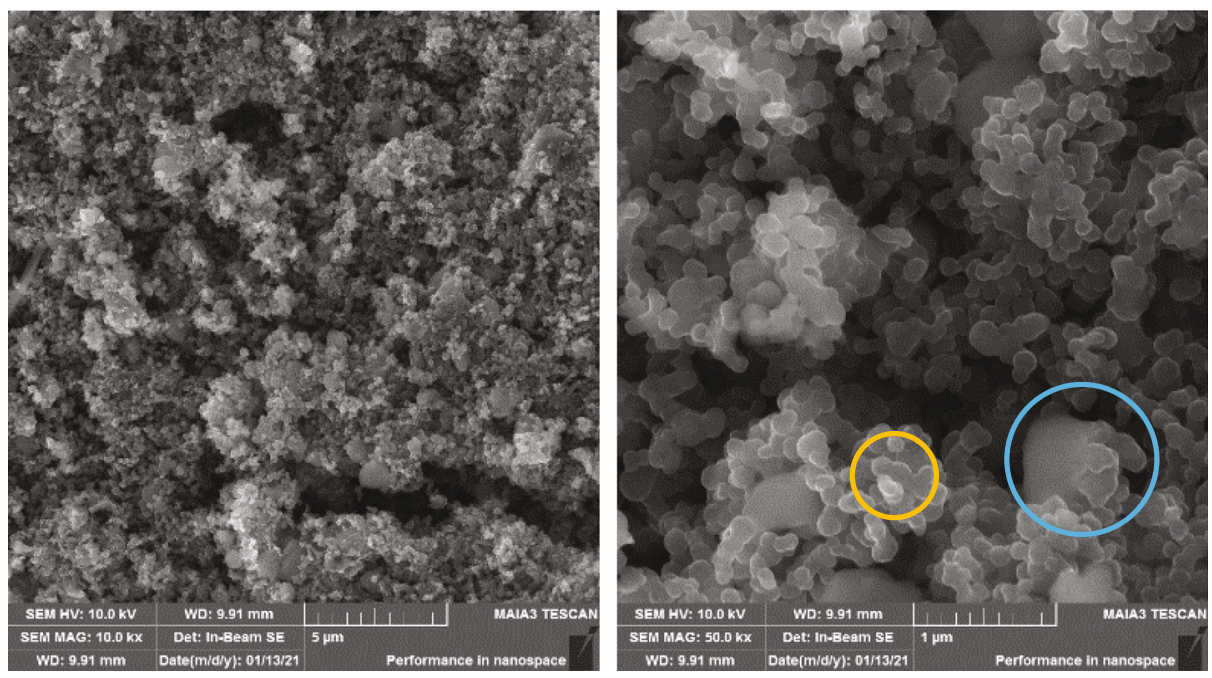

FIGURE 14: SEM of combustion products at gas generator throat.

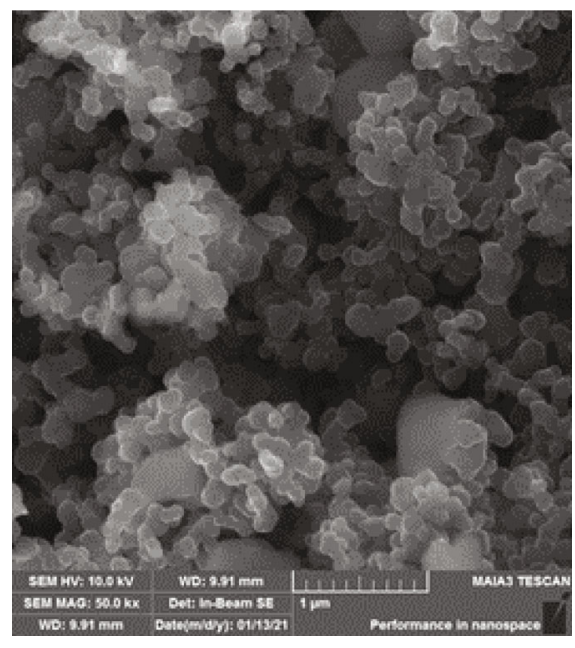

(a) Throat of gas generator

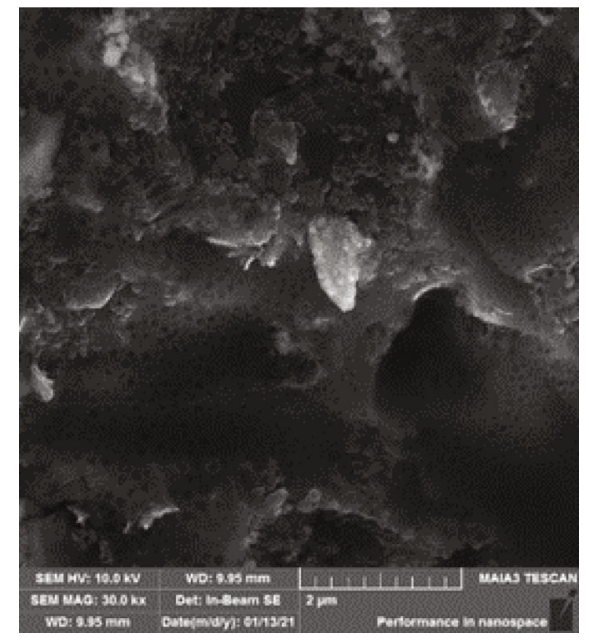

(b) Bottom of back cavity

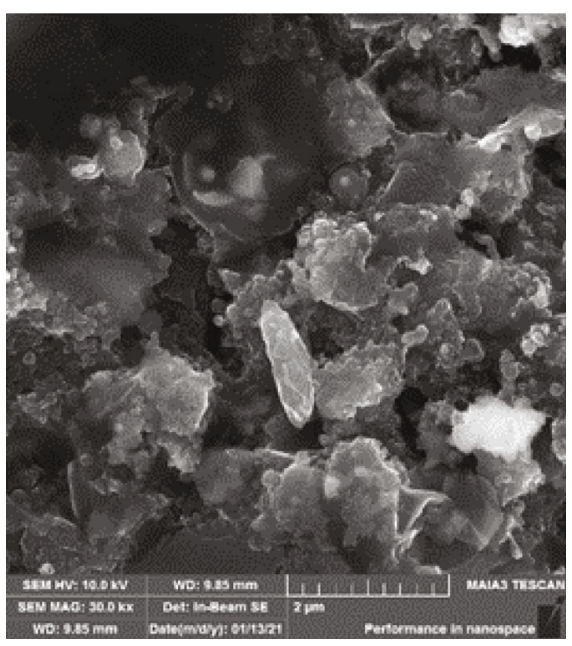

(c) Outlet of combustor

FIGURE 15: SEM of the products in different positions. 

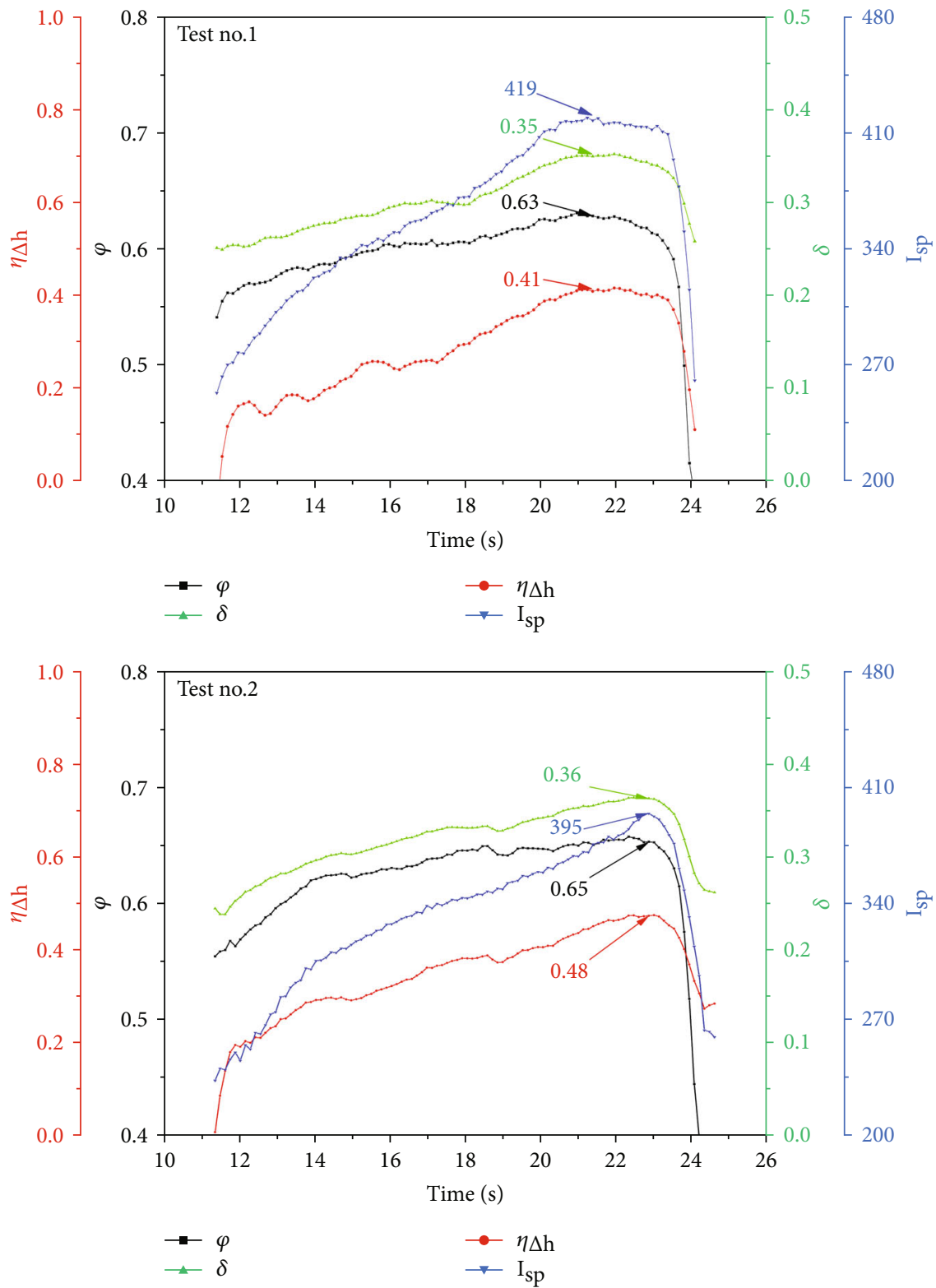

FIGURE 16: Evolution of SSRJ combustor performance during the two tests.

the NASA thermodynamic calculation software CEA [35]. Using the mass flow rates of air, alcohol, and oxygen measured during the test, the total temperature at the inlet of the isolator, $\left(T_{t, \exp }\right)_{\text {in }}$, can also be calculated using CEA.

In order to calculate the test total temperature $\left(T_{t, \exp }\right)_{e}$, the Mach number $\mathrm{Ma}_{e}$ is obtained first using the following:

$$
F=\dot{m}_{e} v_{e}+\left(p_{e}-p_{a}\right) A_{e}
$$

where $F$ is the thrust, $p_{e}$ is the measured pressure, and $p_{e}$ and $A_{e}$ are the atmospheric pressure and outlet area, respectively. The $\dot{m}_{e}$ is determined as follows:

$$
\dot{m}_{e}=\dot{m}_{\mathrm{air}}+\dot{m}_{\mathrm{fuel}}=\rho_{e} v_{e} A_{e}
$$

The gas state equation and Mach number can be dis- played as follows:

$$
\begin{gathered}
p_{e}=\rho_{e} R_{e} T_{e}, \\
\mathrm{Ma}_{e}=\frac{v_{e}}{\sqrt{\gamma_{e} R_{e} T_{e}}},
\end{gathered}
$$

where $\rho_{e}, R_{e}$, and $\gamma_{e}$ are the density, gas constant, and specific heat ratio, respectively, which are calculated by the CEA.

Therefore, the Mach number $\mathrm{Ma}_{e}$ can be calculated as follows:

$$
\mathrm{Ma}_{e}=\left(\frac{F-\left(p_{e}-p_{a}\right) A_{e}}{\gamma_{e} p_{e} \mathrm{Ma}_{e}}\right)^{1 / 2}
$$


The test total temperature $\left(T_{t, \exp }\right)_{e}$ can be displayed as follows:

$$
\left(T_{t, \exp }\right)_{e}=T_{e}\left(1+\frac{\gamma_{e}-1}{2} \mathrm{Ma}_{e}^{2}\right) .
$$

The total pressure recovery coefficient $\delta$ is defined as the ratio of the total pressure at the outlet $p_{t, e}$ and inlet $p_{t, \text { in }}$ of the isolator [34]:

$$
\delta=\frac{p_{t, e}}{p_{t, \text { in }}}
$$

The total pressure at the outlet is derived from the following:

$$
p_{t, e}=p_{e}\left(1+\frac{\gamma_{e}-1}{2} \mathrm{Ma}_{e}^{2}\right)^{\gamma_{e} / \gamma_{e}-1}
$$

The $p_{t, \text { in }}$ is the measured pressure of the air heater.

The thrust specific impulse is defined as follows:

$$
I_{s p}=\frac{F-F_{a h}}{\dot{m}_{\text {fuel }} \cdot g},
$$

where $F_{a h}$ is the thrust value with the heater working steadily.

It should be noted that, given the limitations imposed by the measurement means and the three-dimensional flow characteristics of the combustor, all the variables calculated by the above formula replace the average or integral value of a certain section with the wall pressure. However, this is one of the most common methods for scramjet performance calculations.

The performance of the SSRJ combustor during the two tests, calculated using the abovedescribed method, is shown in Figure 16. The performance at the maximum specific impulse of the thrust rise is shown in Table 3.

The results show that there is a continuous improvement of the combustor performance during both tests, and thus, the fuel-rich mixture is burned more completely. This is consistent with the observed change in the exhaust plume (Figure 9). Interestingly, the change trend of the total pressure recovery coefficient and the combustion efficiency is the same. Our analysis suggests that this is caused by the continuous forward shock train in the isolator (Figure 9), which reduces the flow velocity in the combustor. Compared to the flame-holding cavity used in test 1 , the combination of narrow and lobe cavities in test 2 is more conducive to the combustion of the fuel-rich mixture. The maximum combustion efficiency of the test increased from 0.41 to 0.48 , while the total pressure recovery coefficient was basically the same, about 0.35 . However, the specific impulse of the thrust augmentation decreased from $419 \mathrm{~s}$ to $395 \mathrm{~s}$, indicating that shapes of the narrow and lobe cavities produce a thrust drop.

The thermal calculation results show that the energy of the gas only accounts for about $25 \%$ of the total energy of
TABle 3: Performance parameters of the scramjet combustor.

\begin{tabular}{lccccccc}
\hline Test no. & $\varphi$ & $I_{s p} / s$ & $\mathrm{Ma}_{e}$ & $T_{t, \exp } / k$ & $T_{t, \text { the }} / k$ & $\delta$ & $\eta$ \\
\hline 1 & 0.63 & 419 & 1.37 & 1887 & 2754 & 0.35 & 0.41 \\
2 & 0.65 & 395 & 1.32 & 1940 & 2754 & 0.36 & 0.48 \\
\hline
\end{tabular}

the fuel-rich mixture, and the remaining energy is stored in the particles, especially boron particles account for a large proportion. Therefore, the low combustion efficiency of particles has become a key factor in limiting the performance of the engine, which suggests that further study of the combustion characteristics of a SSRJ is imperative.

The scope for future research would be the optimization of the cavity size, location, number, and other parameters according to the different characteristics of gas and particles in the fuel-rich mixture, to further improve the performance of SSRJ. In addition, considering that the test can obtain less information, which is not conducive to the analysis of the inner flow field, the numerical calculation of the SSRJ should also be studied.

\section{Conclusions}

In this paper, the direct-connected tests on a solid scramjet combustor were performed by utilizing a boron-based solid propellant. The working characteristics of a multicavity solid scramjet were studied. The effects of different cavity shapes on the performance of a solid scramjet were compared. The test simulates a flight environment of Mach 5.5 at a $25 \mathrm{~km}$ altitude. Based on the registered test data and the analysis of the exhaust plume, the ablation of the cavity, and the scanning electron microscope images of the condensed products, the following conclusions are obtained:

(a) The solid scramjet combustor was proposed in this paper which can significantly improve the ignition performance of the fuel-rich mixture and the cavity can maintain the high-pressure environment in the combustor

(b) The combustion of the fuel-rich mixture in the combustor has the typical characteristics of an establishment-development-keep-attenuation cycle

(c) The combustion of the gas in the fuel-rich mixture is rapid, and the particles exist in the form of agglomerates. The particle size is in the order of micrometers, and the fluidity is good

(d) Compared to the flame-holding cavity, the combination of narrow cavity and lobe cavity is more conducive for mixing and combustion. The highest combustion efficiency increased from 0.41 to 0.48 , and the total pressure recovery is about 0.36

Further research needs to optimize the cavity size, location, number, and other parameters according to the different characteristics of gas and particles in the fuel-rich mixture, to improve the performance of solid scramjet. The 
numerical calculation of the solid scramjet should also be studied.

\section{Data Availability}

No data were used to support this study.

\section{Conflicts of Interest}

The authors declare there are no conflicts of interest regarding the publication of this paper.

\section{Acknowledgments}

This work has been financially supported by the Hunan Provincial Natural Science Foundation (No. 2020JJ4665) and the National Natural Science Foundation of China (Grant No. 52006240). The authors would like to express their gratitude to EditSprings (https://www.editsprings.com/) for the expert linguistic services provided.

\section{References}

[1] B. Xu and Z. Shi, "An Overview on Flight Dynamics and Control Approaches for Hypersonic Vehicles," Science ChinaInformation Sciences, vol. 58, no. 7, pp. 1-19, 2015.

[2] R. K. Seleznev, "History of scramjet propulsion development," Journal of Physics: Conference Series, vol. 1009, article 012028, 2018.

[3] N. Das, K. M. Pandey, and K. K. Sharma, "A brief review on the recent advancement in the field of jet engine - scramjet engine," Materials Today: Proceedings, vol. 45, pp. 68576863, 2021.

[4] S. Kumar, K. Murari Pandey, and K. Kumar Sharma, "Recent developments in technological innovations in scramjet engines: a review," Materials Today: Proceedings, vol. 45, pp. 6874-6881, 2021.

[5] X. Zhao, Z. Xia, B. Liu, Z. Lv, and L. Ma, "Numerical study on solid-fuel scramjet combustor with fuel-rich hot gas," Aerospace Science and Technology, vol. 77, pp. 25-33, 2018.

[6] V. V. Tyurenkova and L. I. Stamov, "Flame propagation in weightlessness above the burning surface of material," Acta Astronautica, vol. 159, pp. 342-348, 2019.

[7] A. G. Kushnirenko, L. I. Stamov, V. V. Tyurenkova, M. N. Smirnova, and E. V. Mikhalchenko, "Three-dimensional numerical modeling of a rocket engine with solid fuel," Acta Astronautica, vol. 181, pp. 544-551, 2021.

[8] V. Volokhov, P. Toktaliev, S. Martynenko, L. Yanovskiy, A. Volokhov, and D. Varlamov, "Supercomputer simulation of physicochemical processes in solid fuel ramjet design components for hypersonic flying vehicle," in Russian Supercomputing Days, Springer, Cham, 2016.

[9] R. Ben-Arosh, B. Natan, E. Spiegler, and A. Gany, "The Reacting Flowfield within a Supersonic Combustion Solid Fuel Ramjet," in 33rd Joint Propulsion Conference and Exhibit, Seattle, WA, U.S.A., 1997.

[10] A. Ben-Yakar, B. Natan, and A. Gany, "Investigation of a solid fuel scramjet combustor," Journal of Propulsion and Power, vol. 14, no. 4, pp. 447-455, 1998.

[11] X. Zhao, Z. Xia, L. Ma et al., "Research progress on solid-fueled scramjet," Chinese Journal of Aeronautics, 2021.
[12] W. Jung, S. Baek, J. Park, and S. Kwon, "Combustion characteristics of ramjet fuel grains with boron and aluminum additives," Journal of Propulsion and Power, vol. 34, no. 4, pp. 1070-1079, 2018.

[13] O. Musa, L. Weixuan, C. Xiong, G. Lunkun, and L. Wenhe, "Experimental investigation on the effect of swirling flow on combustion characteristics and performance of solid fuel ramjet," Acta Astronautica, vol. 148, pp. 163-174, 2018.

[14] H. Zhang, N. Wang, Z. Wu, W. Han, and R. Du, "A new model of regression rate for solid fuel scramjet," International Journal of Heat and Mass Transfer, vol. 144, p. 118645, 2019.

[15] Z. Lv, Z. Xia, B. Liu, and Y. Liu, "Experimental and numerical investigation of a solid-fuel rocket scramjet combustor," Journal of Propulsion and Power, vol. 32, no. 2, pp. 273-278, 2016.

[16] C. Li, Z. Xia, L. Ma, X. Zhao, and B. Chen, "Numerical study on the solid fuel rocket scramjet combustor with cavity," Energies, vol. 12, no. 7, p. 1235, 2019.

[17] Z. Lv, Z. Xia, B. Liu, and L. Huang, "Preliminary experimental study on solid-fuel rocket scramjet combustor," Journal of Zhejiang University-SCIENCE A, vol. 18, no. 2, pp. 106-112, 2017.

[18] L. Yang, G. Yonggang, S. Lei, C. Zexin, and Y. Xiaojing, "Preliminary experimental study on solid rocket fuel gas scramjet," Acta Astronautica, vol. 153, pp. 146-153, 2018.

[19] V. A. Levin, N. A. Lutsenko, E. A. Salgansky, and L. S. Yanovskiy, "A model of solid-fuel gasification in the combined charge of a low-temperature gas generator of a flying vehicle," Doklady Physics, vol. 63, no. 9, pp. 375-379, 2018.

[20] Y. Liu, Y. Gao, Z. Chai, Z. Dong, C. Hu, and X. Yu, "Mixing and heat release characteristics in the combustor of solid-fuel rocket scramjet based on DES," Aerospace Science and Technology, vol. 94, p. 105391, 2019.

[21] L. Huang, G. Hu, B. Hu, L. Tian, and Y. Yang, "Experiment on combustion of solid rocket scramjet," Journal of Solid Rocket Technology, vol. 43, no. 200, pp. 5-9, 2020.

[22] Z. Liu, L. Chen, and Q. Wu, "Configuration effects analysis of the second combustor of the solid rocket scramjet," Journal of Solid Rocket Technology, vol. 40, p. 5, 2017.

[23] G. Yonggang, L. Yang, C. Zexin, L. Xiaocong, H. Chunbo, and Y. Xiaojing, "Influence of lobe geometry on mixing and heat release characteristics of solid fuel rocket scramjet combustor," Acta Astronautica, vol. 164, pp. 212-229, 2019.

[24] C. Li, Z. Xia, L. Ma, X. Zhao, and B. Chen, "Experimental and numerical study of solid rocket scramjet combustor equipped with combined cavity and strut device," Acta Astronautica, vol. 162, pp. 145-154, 2019.

[25] C. Li, X. Zhao, Z. Xia, L. Ma, and B. Chen, "Influence of the vortex generator on the performance of solid rocket scramjet combustor," Acta Astronautica, vol. 164, pp. 174-183, 2019.

[26] J. Liu, N.-f. Wang, J. Wang, and Z.-y. Li, “Optimizing combustion performance in a solid rocket scramjet engine," Aerospace Science and Technology, vol. 99, p. 105560, 2020.

[27] M. Li-kun, L. Chao-long, X. Zhi-xun, and Z. Xiang, "Experimental Investigation of Solid Rocket Scramjet Combustor with Cavity Flameholder," Journal of Propulsion Technology, vol. 42, pp. 319-326, 2021.

[28] A. Ben-Yakar and R. K. Hanson, "Cavity flame-holders for ignition and flame stabilization in scramjets: An overview," Journal of Propulsion and Power, vol. 17, no. 4, pp. 869-877, 2001. 
[29] M. B. Sun, C. Gong, S. P. Zhang, J. H. Liang, W. D. Liu, and Z. G. Wang, "Spark ignition process in a scramjet combustor fueled by hydrogen and equipped with multi-cavities at Mach 4 flight condition," Experimental Thermal and Fluid Science, vol. 43, pp. 90-96, 2012.

[30] X. P. Li, W. D. Liu, L. C. Yang, B. An, Y. Pan, and J. J. Zhu, "Experimental investigation on fuel distribution in a scramjet combustor with dual cavity," Journal of Propulsion and Power, vol. 34, no. 2, pp. 552-556, 2018.

[31] Z. Cai, T. Wang, and M. Sun, "Review of cavity ignition in supersonic flows," Acta Astronautica, vol. 165, pp. 268-286, 2019.

[32] G. Choubey, Y. Devarajan, W. Huang, K. Mehar, M. Tiwari, and K. M. Pandey, "Recent advances in cavity-based scramjet engine- a brief review," International Journal of Hydrogen Energy, vol. 44, no. 26, pp. 13895-13909, 2019.

[33] W. Ao, Y. Wang, and S. Wu, "Ignition kinetics of boron in primary combustion products of propellant based on its unique characteristics," Acta Astronautica, vol. 136, pp. 450-458, 2017.

[34] C. Li, Z. Xia, L. Ma, X. Zhao, B. Chen, and P. Yang, "Performance evaluation for scramjet based on ground directconnected test: a method investigation," Aerospace Science and Technology, vol. 117, p. 106895, 2021.

[35] S. Gordon and B. J. McBride, Computer program for calculation of complex chemical equilibrium compositions and applications. Part 1: Analysis, NASA Center for Aerospace Information (CASI), United States, 1994. 